\title{
Neuroma traumático em nervo alveolar inferior: relato de caso
}

\author{
Traumatic neuroma in inferior alveolar nerve: case report \\ El neuroma traumático en nervio alveolar inferior: reporte de un caso \\ Henrique Celestino Lima e SILVA ${ }^{\mathbf{1}}$ \\ Roberto MORENO ${ }^{2}$ \\ Sérgio Luís de MIRANDA ${ }^{3}$
}

\author{
${ }^{I}$ Especialista em Cirurgia e Traumatologia Buco-Maxilo-Facial (CTBMF) \\ Mestrando do Programa de Pós-Graduação em Odontologia da Universidade Federal de Mato Grosso do Sul - UFMS. \\ ${ }^{2}$ Especialista em Cirurgia e Traumatologia Buco-Maxilo-Facial (CTBMF), \\ Mestrado em Medicina (Otorrinolaringologia) Universidade Federal de São Paulo, UNIFESP, Brasil, \\ Doutorando em Medicina (Otorrinolaringologia) Universidade Federal de São Paulo, UNIFESP, Brasil, \\ Cirurgião Buco-Maxilo-Facial dos Hospitais São Luiz do Morumbi, Itaim e Hospital Israelita Albert Einstein \\ ${ }^{3}$ Especialista em Cirurgia e Traumatologia Buco-Maxilo-Facial (CTBMF), \\ Especialista em Otorrinolaringologia, Cirurgia de Cabeça e Pescoço, \\ Mestrado e Doutorado em Otorrinolaringologia e Cirurgia de Cabeça e Pescoço pela Universidade Federal de São Paulo, UNIFESP, Brasil, \\ Cirurgião Crânio-Maxilo-Facial dos Hospitais São Luiz do Morumbi, Itaim e Hospital Israelita Albert Einstein
}

\section{Resumo}

O termo neuroma traumático é usado para descrever a formação de uma massa que se desenvolve nas extremidades dos cotos nervosos, após corte parcial ou completo do nervo. A lesão representa uma resposta exagerada, por uma hiperplasia reativa como resultado de tentativas de regeneração, caracterizada por hiperplasia de células de Schwann. O neuroma traumático já foi descrito com outras origens, como danos nervosos causados por pressão, lesão por esmagamento, lacerações, alongamento, sangramento no tecido que circunda do nervo, infecção e isquemia.

Descritores: Neuroma; Hiperplasia; Células de Schwann.

\begin{abstract}
The term traumatic neuroma is used to describe the formation of masses that develop at the ends of proximal nerve stumps after partial or complete nerve. The lesion represents an exaggerated response and is a reactive hyperplasia resulting from abortive attempts at regeneration characterized by hyperplasia of irregularly arranged schwann cells. Traumatic neuroma can result from nerve damage caused by pressure, crushing injuries, cuts, lacerations, stretching, bleeding into the tissue surrounding the nerve, infection, and ischemia.
\end{abstract}

Descriptors: Neuroma; Hyperplasia; Schwann Cells.

\section{Resumen}

El término neuroma traumático se utiliza para describir la formación de la masa que se desarrollan en los extremos de los troncos de los nervios después de la sección parcial o completa del nervio. La lesión es una respuesta exagerada, la generación de una hiperplasia reactiva como resultado de los intentos de regeneración, caracterizado por hiperplasia de las células de Schwann. El neuroma traumático ha sido descrita con otras fuentes, tales como daños en los nervios por presión, heridas por aplastamiento, laceraciones, estiramiento, sangrado en el tejido que rodea a la infección del nervio y la isquemia.

Descriptores: Neuroma; Hiperplasia; Células de Schwann. 


\section{INTRODUÇÃO}

Neuroma traumático não é um neoplasma verdadeiro, mas sim uma proliferação reacional do tecido neural após transecção ou dano de um feixe nervoso ${ }^{1}$. Depois de um nervo ser danificado ou lesionado, a porção proximal tenta regenerar-se e reestabelecer a inervação do segmento distal pelo crescimento de axônios atraves de tubulos de células proliferantes de Shawann ${ }^{1,2,3}$. Se estes elementos regeneradores encontram um tecido cicatricial ou por outro lado não podem reestabelecer a inervação, pode se desenvolver uma massa semelhante a um tumor no local da injúria ${ }^{1,4-6}$.

Eles se desenvolvem em qualquer localização, frequentemente, é possivel estabelecer uma historia de trauma e podem ocorrer em qualquer idade, mas são diagnosticados, com mais frequencia, em adultos de meia-idade ${ }^{1}$. Ligeiramente mais comun no sexo feminino $^{7,8}$.

Na região da cabeça e pescoço os neuromas são relatados com mais frequência após a parotidectomia e esvaziamento cervical, e por sua vez, menos descritos assossiados a osteotomias mandibulares e exodontias 9 . Intraoral podem ser mais observados relacionados ao forame mental $^{10}$, lábio inferior ${ }^{11}$ e língua ${ }^{12}$, já os neuromas-ósseos relacionados a exodontia de terceiros molares inferiores, são raramente citados na literatura1 $^{1}$ Embora a dor tradicionalmente seja considerada uma caracteristica desta lesão, estudos indicam que somente um quarto dos neuromas traumáticos são dolorosos, esta dor pode ser intermitente ou constante, e varia de uma leve sensibilidade ou queimação, a uma dor forte $\operatorname{irradiada}^{1,2}$.

O propósito do artigo é apresentar um caso raro de neuroma intra-ósseo do nervo alveolar inferior após a exodontia de terceiro molar inferior direito e determinar o diagnóstico, plano terapêutico e proporcionar uma discussão sobre a apresentação clínica, achados de imagem, manejo terapêutico e uma revisão da literatura destas lesões raras.

\section{CASO CLÍNICO}

Paciente de 33 anos de idade, sexo feminino, leucoderma procurou a clínica particular da equipe para a exodontia dos terceiros molares superiores e inferiores. Foi realizado o exame clínico e solicitado exames de imagem (Rx Panorâmco) e laboratoriais de rotina (Figuras 1 e 2). Após a avaliação, a mesma foi medicada para realizar a cirurgia de exodontia dos elementos dentarios 18, 28, 38 e 48. Cirurgia sem intercorrencia e a mesma foi encaminhada para resindência com retorno ambulatorial em uma semana. Paciente sem queixas no primeiro retorno, onde foi realizada a remoção dos pontos cirurgicos. Após três semanas a mesma começou a relatar sintomatologia dolorosa em região retromolar direita. Apresentava dor na hemiface direita, latejante e contínua, que melhorava parcialmente após analgesia. Não apresentava febre, hipoestesia na face, nem alteração da musculatura mastigatória. Os exames neurológico e leucograma eram normais. Não apresentava manifestações cutâneas ou história familiar sugestiva de neurofibromatose. $\mathrm{Na}$ investigação diagnóstica, a radiografia panorâmica e a tomografia computadorizada de face (TC) mostraram imagens sugestivas de neoplasia. A radiografia panorâmica revelou lesão radiolúcida unilocular, circunscrita, com limites bem definidos, com alargamento do mesmo na confluência ascendente ângulo direito do ramo (Figura 3). A tomografia computadorizada (TC) revelou a existência de uma lesão hipoatenuante, bem definida, oval, expansiva em canal do nervo alveolar inferior direito, causando ampliação do mesmo (Figuras 4 e 5).

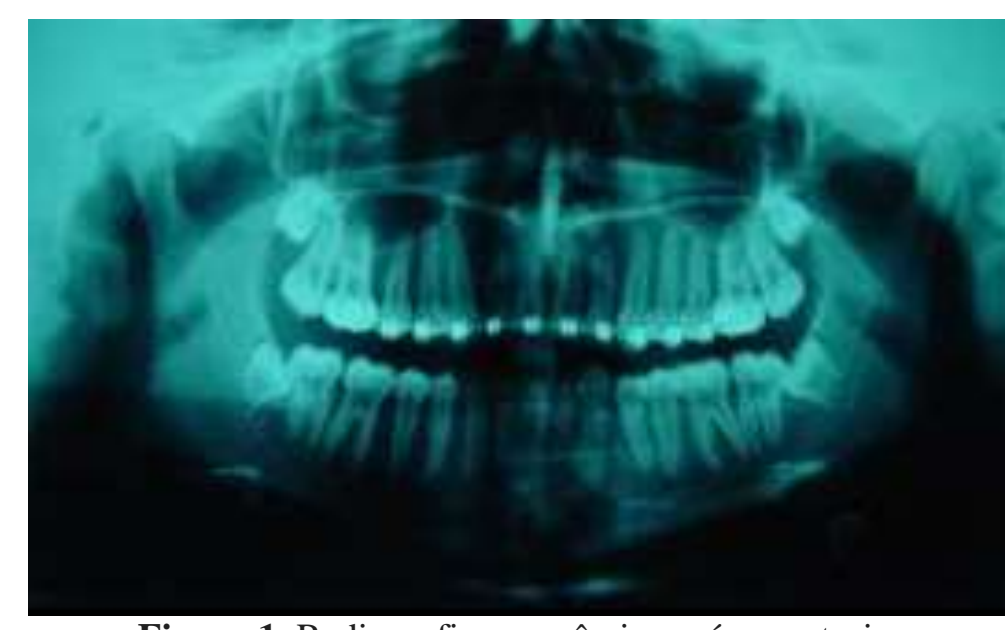

Figura 1. Radiografia panorâmica pré-operatoria

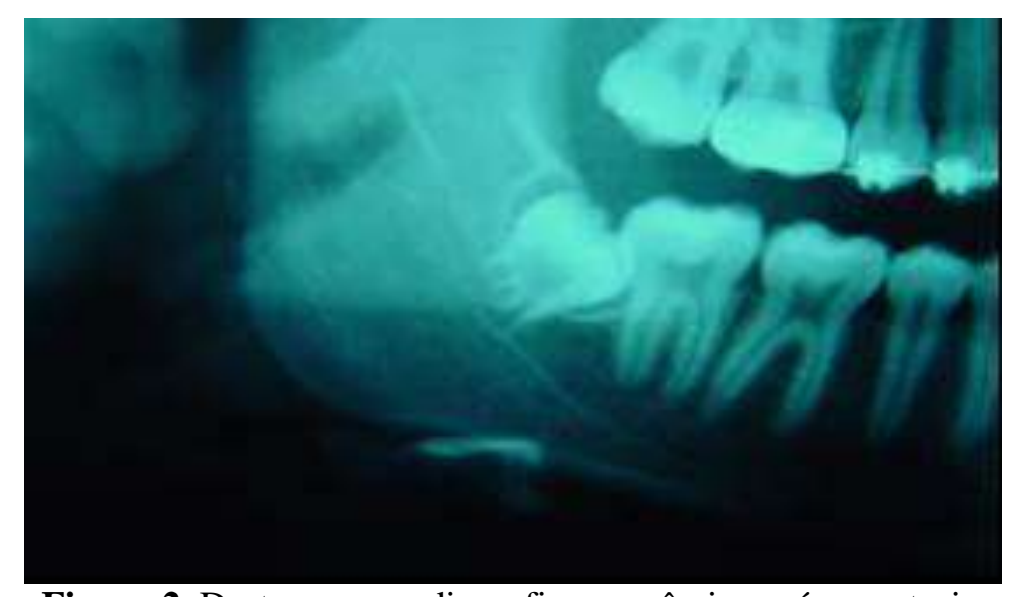

Figura 2. Destaque na radiografia panorâmica pré-operatoria para o íntimo contato entre o nervo alveolar e a lesão

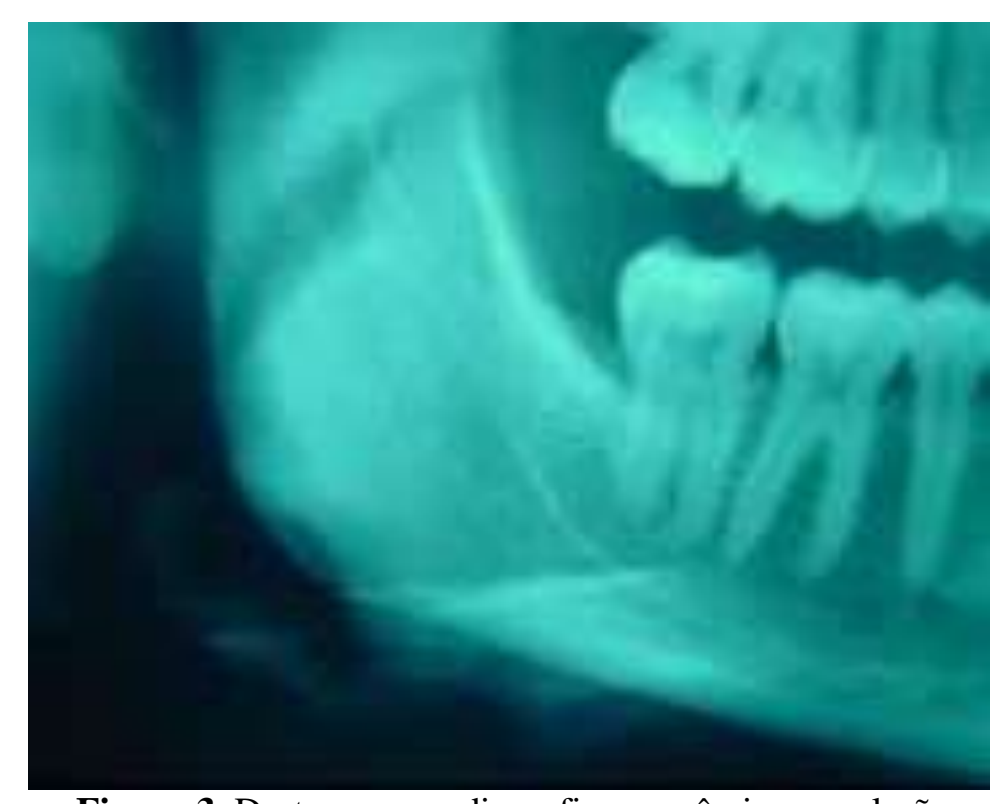

Figura 3. Destaque na radiografia panorâmica para lesão radiolúcida unilocular, circunscrita, com limites bem definidos 


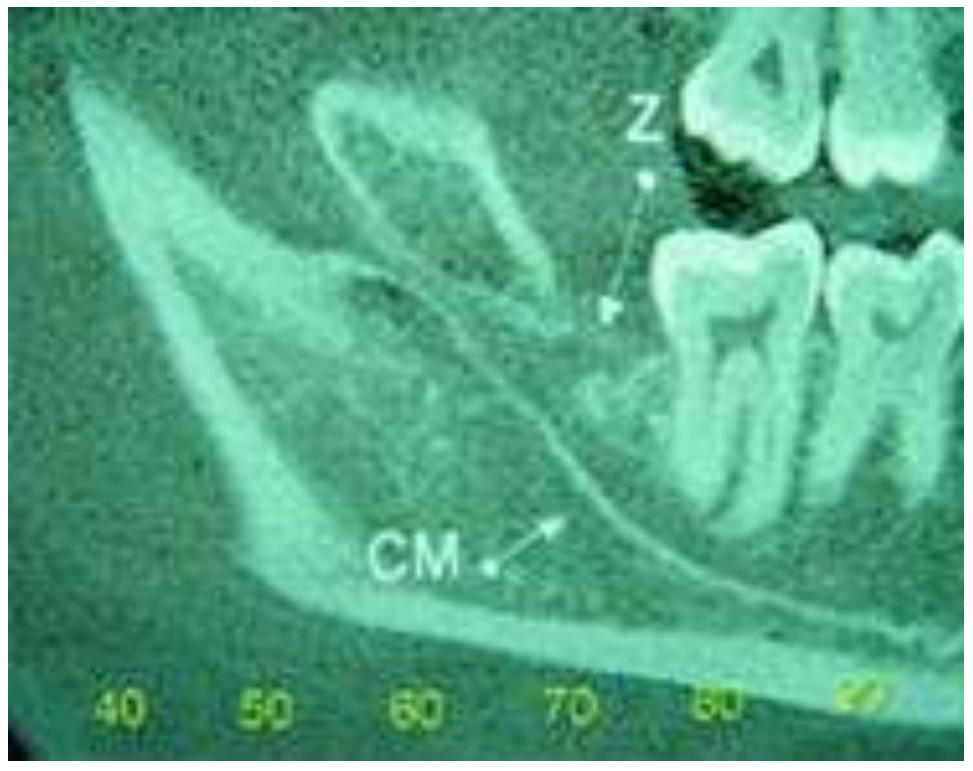

Figura 4. Tomografia computadorizada (TC) revelando lesão hipoatenuante bem definida, oval, expansiva em canal do nervo alveolar inferior

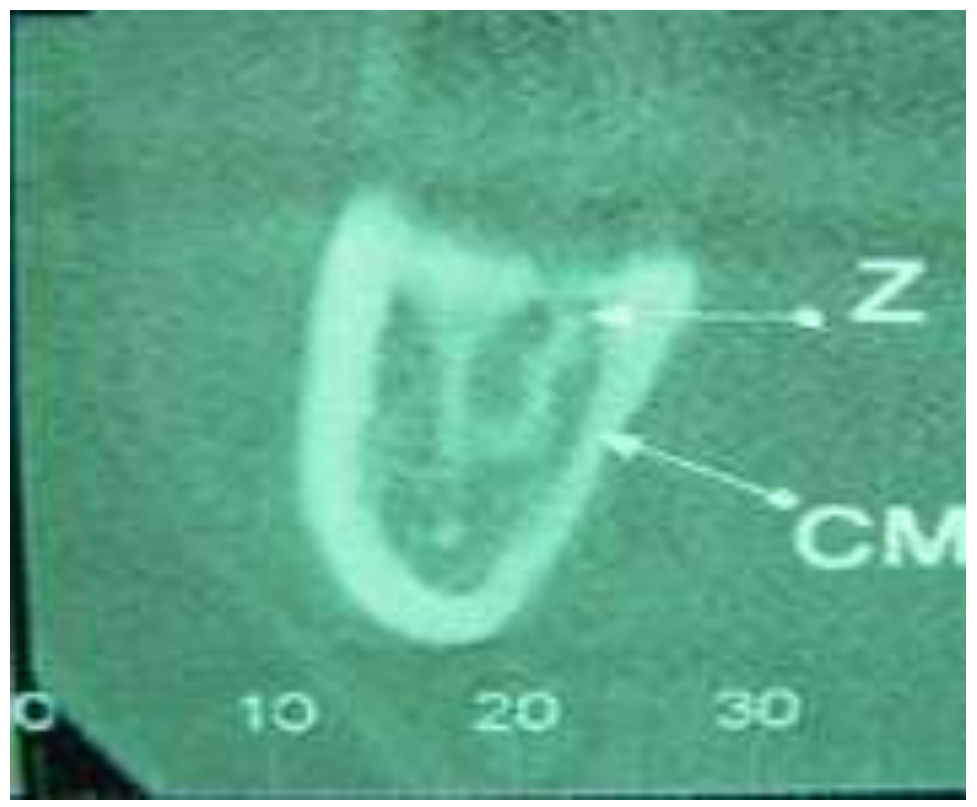

Figura 5. Tomografia computadorizada (TC): ampliação do canal do nervo alveolar inferior

Dadas às conclusões descritas foi realizada a cirurgia para a biópsia, a mesma foi realizada sob anestesia local, incisão vestibular e osteotomia da parede vestibular da mandíbula, alcançando o sitio da lesão, onde foi realizada dissecção com eletrodo do tipo colorado com ponta agulha reta e exérese da lesão. A dissecção foi simples devido ao encapsulamento do tumor, limites bem definidos e com plano de clivagem, características que permitiram a sua exérese completa, poupando o nervo alveolar inferior (Figuras 6 e 7).

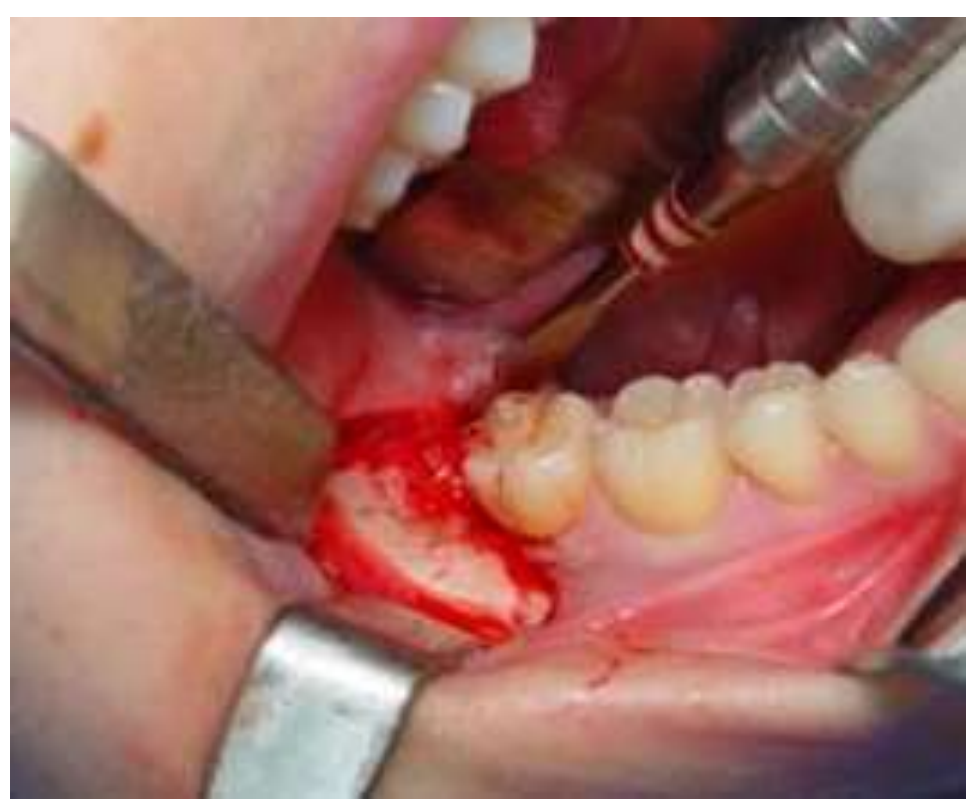

Figura 6. Incisão vestibular e osteotomia da parede vestibular da mandíbula

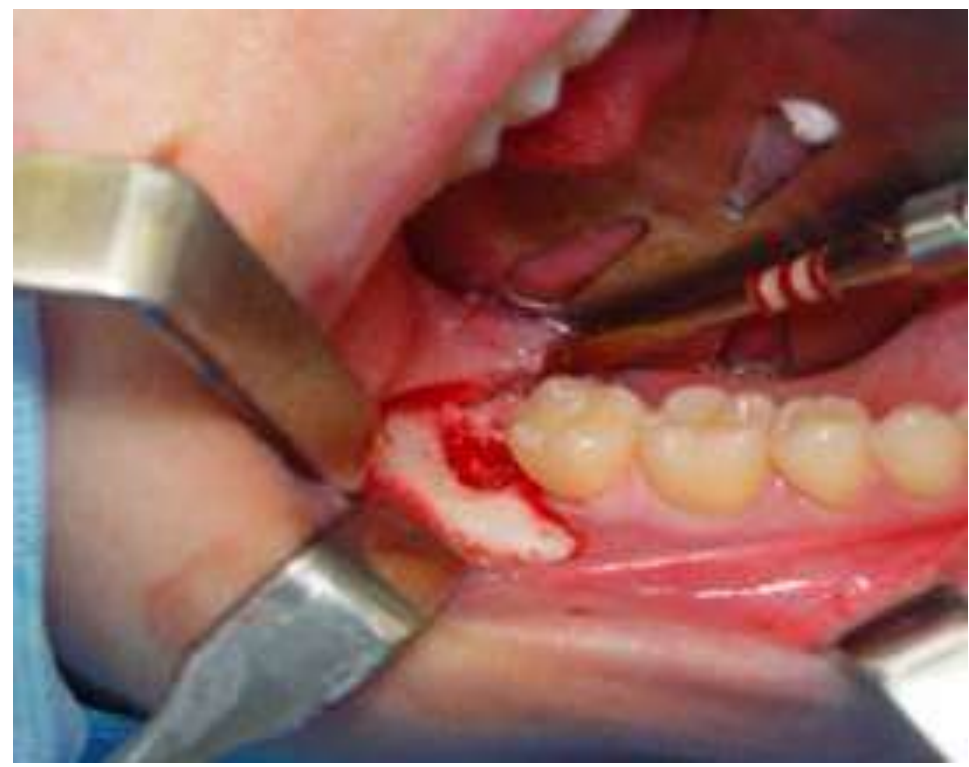

Figura 7. Dissecção com eletrodo do tipo colorado com ponta agulha reta e exérese da lesão

O material foi encaminhado para a análise histopatológica, onde foi confirmado o diagnostico definitivo de neuroma traumático, mostrando uma proliferação ao acaso de feixes nervosos mielinixados maduros dentro de um estroma de tecido conjuntivo friboso, com um leve infiltrado celular, característico de inflamação crônica. Em pós-operatórios de 7, 30, 60 e 150 dias, aspectos de normalidade foram evidenciados, sem queixa estética e/ou funcional.

\section{DISCUSSÃO}

Exitem poucos relatos de neuromas traumáticos na literatura, dessa forma descritos como uma patologia rara ${ }^{1,3,9}$. A sua etiopatogenia é uma resposta exagerada devido a alguma injuria ao nervo, na maioria dos casos após trauma direto ou manipulação cirúrgica, e não são considerados verdadeiras neoplasias em origem ${ }^{13}$. O mecanismo de dano do nervo alveolar inferior pode ser devido a extração dentária, como a do terceiros molares inferiores e a osteotomia sagital da mandibula ${ }^{1,11}$.

A apresentação clinica é muito variavel. O sintoma mais frequiente é a dor, seja nevrálgica ou não-nevrálgica, que pode ser exacerbada por pressão ${ }^{1}$. Outras anomalias sensoriais podem ser observadas na literatura, como as parestesias ${ }^{4,6,10}$. A causa dos sintomas neurológicos mais relatada na literatura é a compressão do nervo pelo tumor, que em virtude do seu crescimento lento pode permitir que mecanismos compensatórios que podem mascarar a sintomatologia por um periodo ${ }^{1,9,14}$.

No diagnóstico diferencial, devem ser analisadas as patologias malignas, que mesmo com pouco relato na literatura, podem causar hipoestesia ou anestesia do nervo alveolar inferior e forte sintomatologia, devido a compressão ou invasão do nervo ${ }^{1}$. Patologias benignas devem ser observadas, como ceratocisto, tumor central de células gigantes, ameloblastoma desmoplásico e fibromas ${ }^{1,6,14}$.

O tratamento de escolha é exérese cirúrgica, com o mínimo de manipulação e destruição fibras 
nervosas, contribuindo para um resultado adequado. A maioria das lesões nao recidivam, em alguns casos, no entanto, a dor persiste ou retorna posteriormente ${ }^{1}$.

Outras opções terapêuticas são menos descritas na literatura, como a radiocirurgia estereotáxica, infiltração local de esteróides e terapia ultra-sônica ${ }^{7}$, já as secções do nervo ou bloqueio com álcool provaram ser ineficazes e podem ser uma terapia prejudicial $^{15}$.

\section{REFERÊNCIAS}

1. Neville BW, Allen CM, Damm DD. Bouquot JE. Patologia: Oral \& Maxilofacial. $2^{\mathrm{a}}$ ed, Rio de Janeiro: Guanabara Koogan; 2004.

2. Sheridan SM. Traumatic neuroma following sagittal split mandibular osteotomy. $\mathrm{Br} \mathrm{J}$ Oral Surg. 1983;21(3):198-200.

3. Kallal RH, Ritto FG, Almeida LE, Crofton DJ, Thomas GP. Traumatic neuroma following sagittal split osteotomy of the mandible. Int $\mathrm{J}$ Oral Maxillofac Surg. 2007;36(5):453-4.

4. Lee EJ, Calcaterra TC, Zuckerbraun L. Traumatic neuromas of the head and neck. Ear Nose Throat J. 1998;77(8):670-74.

5. Huang LF, Weissman JL, Fan C. Traumatic neuroma after neck dissection: $\mathrm{CT}$ characteristics in four cases. AJNR Am J Neuroradiol. 2000;21(9):1676-80.

6. Penarrocha M, Sanchis JM, Orozco M. Acoustic neuroma presenting as orofacial anethesia. Med Oral. 1998;3(3):172-75.

7. Lesoin F, Rousseax M, Villette L, et al. Neurinomas of the trigeminal nerve. Acta Neurochir. 1986;82:118-22.

8. Jimenez BA, Martinez VJM, Bustos RV. Mandibular intraosseous neurinoma. Apropos of a case. Rev Esp Estomatol. 1988;36(3):193-200.

9. Day JD, Fukushima T. The surgical management of trigeminal neuromas. Neurosurgery. 1998;42(2):233-41.

10. Gregg JM. Studies of traumatic neuralgias in the maxillofacial region: surgical pathology and neural mechanisms. J Oral Maxillofac Surg. 1990;48(3):228-37.

11. Torossian JM, Beziat JL, Abou Chebel N, Devouassoux-Shisheboran M, Fischer G. Extracranial cephalic schwannomas: a series of 15 patientes. J Craniofac Surg. 1999;10(5):389-94.

12. Rodríguez JCV, Gutiérrez LMJ, Forcelledo MFF, Arranz JSL. Neck schwannomas. Med Oral. 2003;8(1):71-76.

13. Gibbons SD, Wiesenfeld D. Removal of retromaxillary schwannoma via temporal approach. J Oral Maxillofac Surg. 1991;49(2):1913.
14. Bordi L, Comptom J, Symon L. Trigeminal neuroma: a report of eleven cases. Surg Neurol. 1989;31(4):272-6.

15. Peszkowski MJ, Larsson A. Extraosseous and intraosseous oral traumatic neuromas and their association with tooth extraction. J Oral Maxillofac Surg. 1990;48(9):963-67.

\section{CONFLITO DE INTERESSES}

Os autores declaram não haver conflitos de interesse.

\section{AUTOR PARA CORRESPONDÊNCIA}

Henrique Celestino Lima e Silva

henriquelimacirurgia@gmail.com 